\title{
Does the Coronavirus a Global Threat?
}

\author{
Hüseyin Güdücüoğlư ${ }^{1 *}$, Duygu Korkmaz ${ }^{2}$ \\ ${ }^{1} V$ an Yüzüncü Yul University Faculty of Medicine Department of Medical Microbiology, Van, Turkey \\ ${ }^{2} V$ an Yüzüncü Yul University Faculty of Medicine Department of Biostatistics, Van, Turkey
}

Dear Editor,

At the end of December, 2019; patients presenting with viral pneumonia due to an unidentified microbial agent were reported in Wuhan, China. A novel coronavirus was subsequently identified as the causative pathogen, provisionally named 2019 novel coronavirus (2019-nCoV). 2019-nCoV is sufficiently divergent from SARS-CoV to be considered a new human-infecting beta coronavirus. 2019-nCoV was closely related (with $88 \%$ identity) to two bat-derived severe acute respiratory syndrome (SARS)-like coronaviruses, bat-SL-CoVZC45 and bat-SL-CoVZXC21, collected in 2018 in Zhou Shan, eastern China, however it was more distant from SARS-CoV (about 79\%) and MERS-CoV (about 50\%). According to phylogenetic analysis, bats seem to be the original host of this virus, an animal sold at the seafood market in Wuhan might represent an intermediate host facilitating the emergence of the virus in humans. Importantly, structural analysis suggests that $2019-\mathrm{nCoV}$ might be able to bind to the angiotensin converting enzyme 2 receptor in humans. Urgent investigations are required for future evolution, adaptation, and spread of this virus (1).

On February 11, 2020 the World Health Organization announced an official name for the disease that is causing the 2019 novel coronavirus outbreak, first identified in Wuhan China. The new name of this disease is coronavirus disease 2019, abbreviated as COVID-19. In COVID-19, 'CO' stands for 'corona,' 'VI' for 'virus,' and 'D' for disease. Formerly, this disease was referred to as "2019 novel coronavirus" or "2019-nCoV (2).

In a clinical study (Chen et al., 2020); 99 patients with COVID-19 pneumonia had clinical manifestations of fever (82 [83\%] patients), cough (81 [82\%] patients), shortness of breath (31 [31\%] patients), muscle ache (11 [11\%] patients), confusion (nine [9\%] patients), headache (eight [8\%] patients), sore throat (five [5\%] patients), rhinorrhoea (four [4\%] patients), chest pain (two [2\%] patients), diarrhoea (two [2\%] patients), and nausea and vomiting (one $[1 \%]$ patient). According to imaging examination, 74 (75\%) patients showed bilateral pneumonia (3).

According to centers for disease control and prevention, there is no vaccine against the COVID-19 and people with coronavirus illness need to take some cares such as drink plenty of liquids and stay at home and rest to relieve. In case of occurring severe symptoms, they should be seen a healthcare provider (4).

The thermal camera was started to be used to detect COVID-19 at Istanbul Airport. The body temperature of passengers coming from China was controlled to enter to Turkey. However, does the thermal cameras sufficient for detecting COVID-19?. According to centers for disease control and prevention, the incubation period of this virus is 2-14 days (5) like seasonal flu. Therefore, before coming to the airport checkpoint, passengers may use drug to lower their fever. We can include that measure system is not sufficient and the passengers who came from another country should be checked more serious and sensitive.

The virus has spread to several countries and cities. According to the World Health Organization (Feb 16, 2020): Total confirmed cases number is 51857 . While the total deaths number is 1669 . However, on this date, the total number of cases in other countries was 683, and death was 3 (6).

Considering the number of cases reported between 21 January and 16 February, the number of cases expected to be possible between 17 February and 19 April has been tried to be estimated. Curve estimation method is used as the estimation method. Depending on time, expected number of cases in a one month has been tried to be estimated by linear and quadratic models for China and other countries separately. The determination coefficients for the Quadratic model were found to be $98 \%$ for both China and other countries. Therefore, the model the best fit to the data was a quadratic model. In order to see the difference with the linear model, the linear model results are also given below.

\footnotetext{
*Corresponding Author: Prof. Dr. Hüseyin Güdücüoğlu, Van Yüzüncü Yıl University, Medicine Faculty, Department of Microbiology, $65090 \mathrm{Tuşba/Van}$ 
Table 1. Models for prediction of new cases

\begin{tabular}{lccc}
\hline & Model name & Model & $\mathrm{R}^{2}$ \\
\hline China & Linear & $2646,89 * \mathrm{x}-13768,75$ &, 92 \\
& Quadratic & $-50,73-191,32 * \mathrm{x}+101,36 * \mathrm{x} * \mathrm{x}$ &, 98 \\
& Linear & $22,84 * \mathrm{x}+-112,15$ &, 91 \\
Others & Quadratic & $15,06+-3,48 * \mathrm{x}+0,94 * \mathrm{x} * \mathrm{x}$ &, 98 \\
\hline
\end{tabular}

Table 2. Estimated some case numbers between 20.02-19.04, 2020

\begin{tabular}{ccccc}
\hline & \multicolumn{2}{c}{ China } & \multicolumn{2}{c}{ Others } \\
\hline Dates & Linear & Quadratic & Linear & Quadratic \\
\hline 20.02 .2020 & 68285 & 91430 & 596 & 810 \\
25.02 .2020 & 81519 & 124430 & 710 & 1108 \\
01.03 .2020 & 94754 & 162499 & 824 & 1452 \\
05.03 .2020 & 105341 & 196603 & 915 & 1769 \\
10.03 .2020 & 118579 & 243795 & 1029 & 2191 \\
15.03 .2020 & 131810 & 296055 & 1144 & 2667 \\
20.03 .2020 & 145045 & 353383 & 1258 & 3190 \\
25.03 .2020 & 158279 & 415779 & 13728 & 3760 \\
30.03 .2020 & 171514 & 483244 & 14868 & 4377 \\
05.04 .2020 & 187395 & 570891 & 16238 & 5180 \\
10.04 .2020 & 200629 & 649506 & 1738 & 5900 \\
15.04 .2020 & 213864 & 733189 & 1852 & 6668 \\
19.04 .2020 & 224451 & 803784 & 1943 & 7315 \\
\hline
\end{tabular}

With the Chinese government's effective isolation measures and the world's alarm, the necessary measures regarding the disease have been taken and the outbreak seems as to be under control. However, we can still considered that the threat continues until there is no single patient to be confirmed as a completion of vaccine studies and a reflection of this.

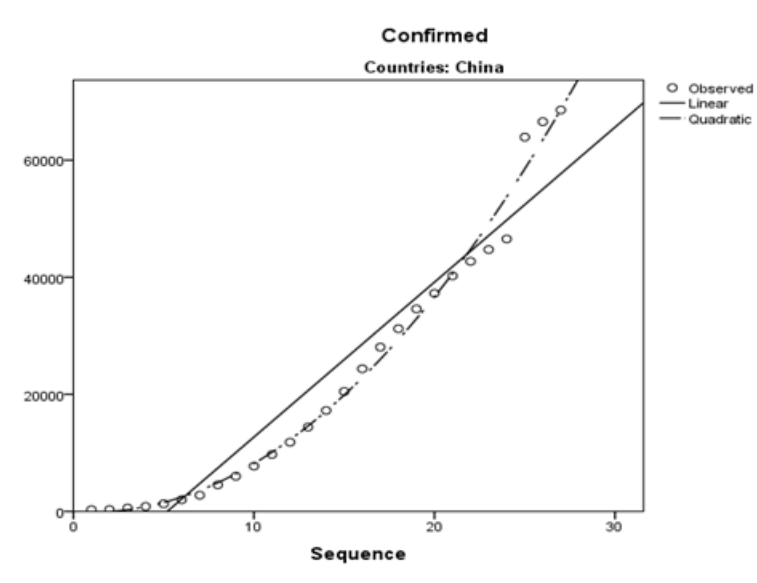

Fig. 1. Curve estimation models for China

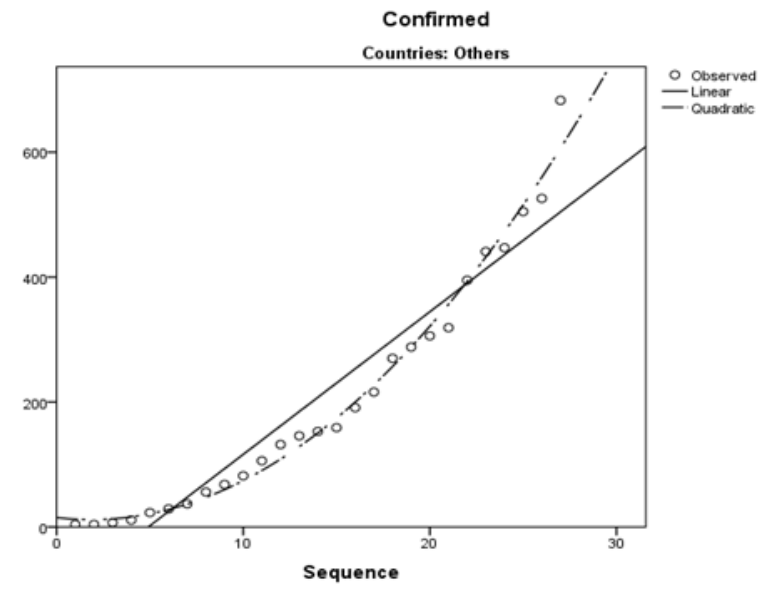

Fig. 2. Curve estimation models for others 


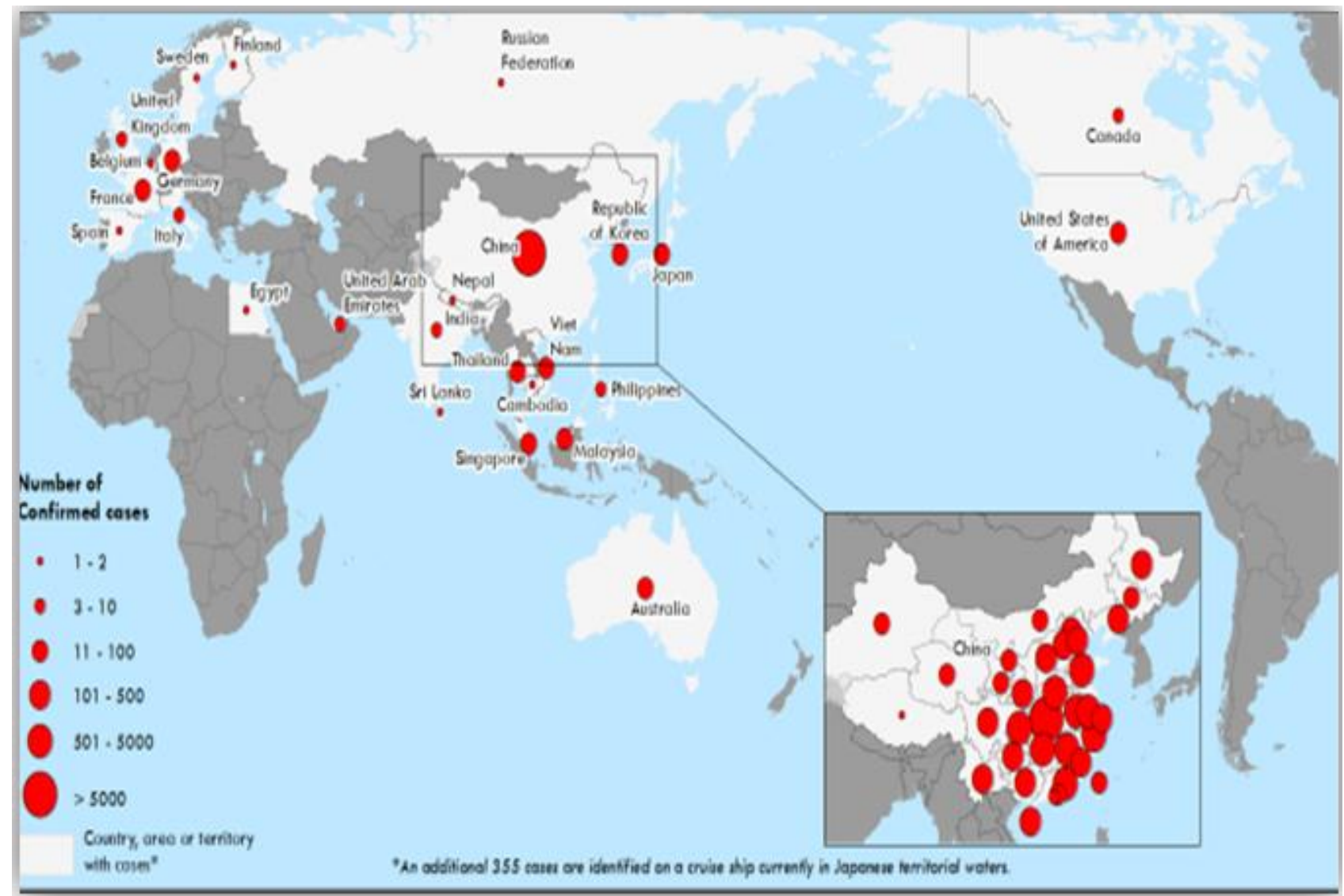

(By World Health Organization February 16, 2020)

\section{Reference}

1. Lu R, Zhao X, Li J, et al. Genomic characterization and epidemiology of 2019 novel coronavirus: implications for virus origins and receptor binding pdf icon[1.35 MB, 10 pages]. The Lancet. Published online January 29, 2020. https://doi.org/10.1016/ S0140-6736(20)30251-8.

2. https://www.cdc.gov/coronavirus/2019-ncov/faq.html

3. Chen N, Zhou M, Dong X, et al. Epidemiological and clinical characteristics of 99 cases of 2019 novel coronavirus pneumonia in Wuhan, China: a descriptive study pdf icon[7 pages]. The Lancet. Published online January 29, 2020. https://doi.org/10.1016/ S0140-6736(20)30211-7.

4. https://www.cdc.gov/coronavirus/2019-ncov/about/prevention-treatment.html

5. https://www.cdc.gov/coronavirus/2019-ncov/about/symptoms.html

6. https://www.who.int/emergencies/diseases/novel-coronavirus-2019/situation-reports 